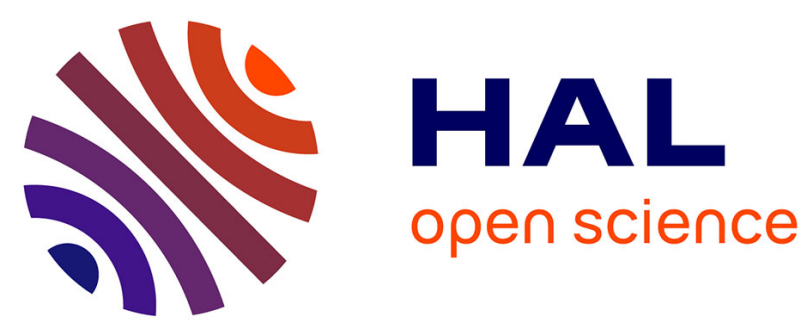

\title{
Evaluating Acceptance of a Haptic Learning Resource from Various Perspectives
}

\author{
Soonja Yeom, Andrew Fluck, Arthur Sale
}

\section{To cite this version:}

Soonja Yeom, Andrew Fluck, Arthur Sale. Evaluating Acceptance of a Haptic Learning Resource from Various Perspectives. 11th IFIP World Conference on Computers in Education (WCCE), Jul 2017, Dublin, Ireland. pp.243-250, 10.1007/978-3-319-74310-3_26 . hal-01762905

\section{HAL Id: hal-01762905 \\ https://hal.inria.fr/hal-01762905}

Submitted on 10 Apr 2018

HAL is a multi-disciplinary open access archive for the deposit and dissemination of scientific research documents, whether they are published or not. The documents may come from teaching and research institutions in France or abroad, or from public or private research centers.
L'archive ouverte pluridisciplinaire HAL, est destinée au dépôt et à la diffusion de documents scientifiques de niveau recherche, publiés ou non, émanant des établissements d'enseignement et de recherche français ou étrangers, des laboratoires publics ou privés. 


\title{
Evaluating Acceptance of a Haptic Learning Resource from Various Perspectives
}

\author{
Soonja Yeom ${ }^{1[0000-0002-5843-101 X]}$, Andrew Fluck ${ }^{2[0000-0003-1301-4615]}$, Arthur Sale ${ }^{1[0000-}$ \\ 0001-7261-8035] \\ ${ }^{1}$ School of Engineering and ICT, University of Tasmania, Australia, ${ }^{2}$ Faculty of \\ Education, University of Tasmania, Australia \\ Soonja.Yeom/Andrew.Fluck/Arthur.Sale@utas .edu.au
}

\begin{abstract}
The Technology Acceptance Model (TAM) was the basis of this study to investigate students' acceptance of a haptic learning resource in anatomy education. Based on the two main elements, perceived ease of use and perceived usefulness of TAM, this study used additional elements such as gender, prior experiences with similar resources, learning preference modes, and enrolled undergraduate courses to investigate students' learning achievement and acceptance. No significant differences were found between genders or enrolled courses in the acceptance of the system in terms of 'ease of use' and 'usefulness' of the system. Students with previous experience with 3D were more favourable to a haptic device, this was statistically significant $(p=.025)$ for "would use" and they also scored higher on the associated quiz ( $p=.050$, Mann-Whitney $U$ test)..
\end{abstract}

Keywords: Learning resource, haptic interface, anatomy learning, Phantom Omni.

\section{Introduction}

Learning resources are important for students to learn efficiently. This is even more so when students have different backgrounds such as prior experiences and varied reactions to the acceptance of technology. Gender, previous experience with 3D or haptic, and/or individual's preferred learning style may matter in the selection of learning resources.

As technology develops, various new learning resources become available to use. One such new resource was developed to give haptic feedback from virtual organs in human anatomy classes [1]. This relatively new resource may help various learners within a resource intensive subject area with somewhat limited opportunities for access to real anatomical specimens [2, 3].

What are the important factors influencing student acceptance of a novel resource? For example, how a learner reacts may vary according to their gender, preferred learning style, or previous experience with a similar type of resource. Students of different genders may accept different models and media differently. Various areas of experiments including olfactory and video media [4], the effect of multisensory of visual and tactile modality [5], gender differences in learning style preferences among undergraduate physiology students [6] and many more are related to the gender 
difference. It is hypothesised that kinaesthetic learners will accept the haptic learning resource more.

Multimodal deep learning has improved effects when compared with unimodal [7]. In order to understand the preferred sensory modality of students for learning anatomy, consenting students were administrated a printed form of version 7.2 of the VARK questionnaire. The VARK instrument is only one of many to measure learning styles or preferences [8] and Rohrer and Pashler [9] have questioned the value of learning styles. However, opportunities to assess kinaesthetic learning in higher education are rare, when the main research question here is to measure the level of acceptance of the haptic device as a tool. Therefore, this study provided an opportunity to investigate applicability for this age range with a haptic device.

Haptic sensory learning resources for dental learning or surgical training have been used $[10,11]$ with $79 \%$ of students benefiting from the study as kinaesthetic learners. This led us to investigate if the haptic sensory learning resource will have a similar effect in anatomy learning, at least for kinaesthetic learners.

\section{Preferences for accepting a haptic learning resource}

\subsection{How the study was performed}

The design research paradigm was adopted to assess acceptance of the hapticanatomy system. The system has evolved as the user tests were done in a cyclic manner. Three different user tests were set up in similar settings with three different student cohorts from 2012 to 2013.

The Technology Acceptance Model (TAM) [15] was the basis for the acceptance questionnaire. TAM posits that usage of technology is influenced by perceived usefulness and ease of use $[2,13,14]$.

Later variant branches came out of the original technology acceptance model from Fred Davis [15] to the theory of reasoned action (TRA) and theory of planned behaviour (TPB) with many extensions or modifications in the technology acceptance field. Haptic enabling technology and TAM is another branch of TRA/TPB focusing more with haptic technology [16].

Ease of use and usefulness are the two important factors used to measure if the users will accept the system in this study which is based on TAM. TAM used a few questions to collect the data. These two main elements are used to measure the acceptance of technology of users. Each element of acceptance was measured based on ease of use and usefulness; then the acceptance was analysed with respect to other variables such as gender, prior experience, personal preferred learning styles, and their enrolled courses.

The questions used in the acceptance assessment survey were re-worded slightly between tests. Nevertheless, the essential questions were the same. A few additional questions were included in the survey as the system evolved. For example, 'were you performing well with the system?', 'did you get mentally stressed while using the system?', 'did you get physically stressed while using the system?', 'Would you use this system as an aid to learning when it is fully developed?', and 'Was the quiz useful as a check on understanding?' However, the focus to discuss here is how the 
system was accepted, based on student gender, preferred learning style, and their prior experiences with any similar sort of interface. The main questions to measure the users' acceptance were: 'was it easy to use the system?'; 'was the system useful?'; and 'would you recommend the system to the university to adopt?'.

The haptic-anatomy system was developed with the Phantom Omni [1]. A forcefeedback pen was gripped by the user, who saw anatomical organs on a screen to learn to identify human internal organs and associated medical nomenclature $[1,12]$. When any part of each organ was held and moved around, the user felt different haptic feedback depending on the hardness and texture of the organ. The three development versions were tested by three different user groups.

The user groups were from three different cohorts with 89 participants including 58 males and 31 females with average age of 20 years old as the system developed further at each cycle according to the design research paradigm [17]. The courses that the users were enrolled in were mainly Bachelor of Medicine / Bachelor of Surgery (MBBS), Bachelor of Education (Health and Physical Education and Outdoor Education), Bachelor of Exercise Science, and Bachelor of Human Movement. Bachelor of Computing students participated in user test 1.The first user test was done with $2^{\text {nd }}$ year students, but the other two user tests were done with $1^{\text {st }}$ year students. Hence our assumption was made that no pre-knowledge was present.

This study was approved by the Social Science Human Research Ethics Committee (HREC) Tasmania Network (reference H001743).

\subsection{Different elements considered: gender, prior experiences, and acceptance}

Gender differences were reported in the fields of education including medical related disciplines [18, 19], but hardly found in anatomy learning. In the area of this study, gender differences were insignificant with respect to questions regarding acceptance, unlike those studies [18, 19] which combined 'useful' and 'easy to use' for this learning resource (Fig. 1.).

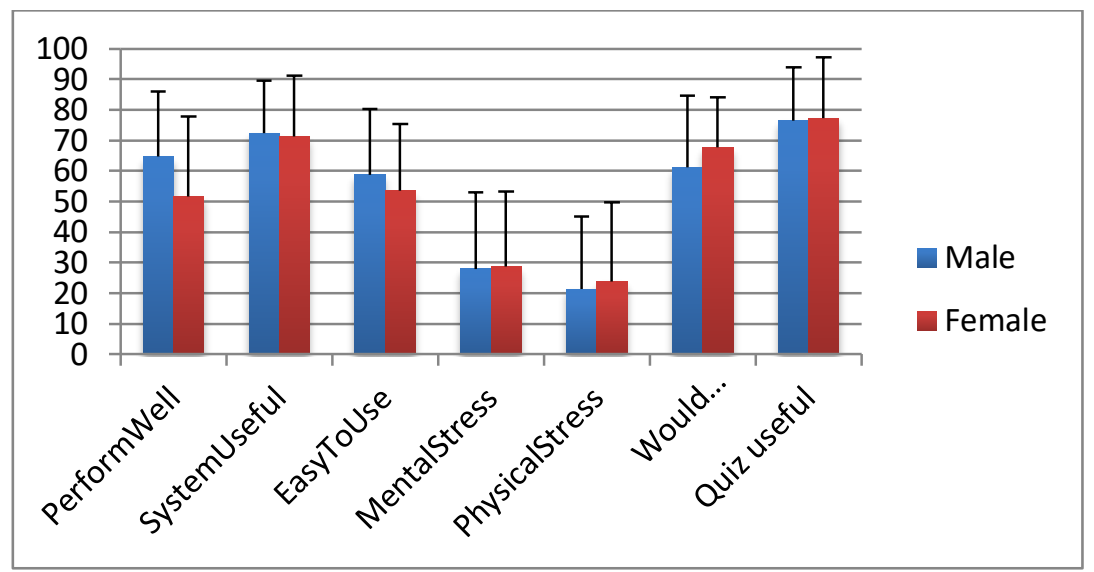

Fig. 1. Gender Comparisons 
Acceptance of the interface was measured from the factors of usefulness, ease of use, and recommendation, which is an additional information provision on top of the normal elements of TAM. This is confirming information of its usefulness if they recommend the system be embedded in their curriculum at the university. A repeated measure ANOVA showed that there was no significant difference by gender, $\mathrm{F}(1,5)=.365, p=.572$, following the Greenhouse-Geisser correction, Epsilon=.068. However, there was a significant difference of haptic interface acceptance, $\mathrm{F}(2,10)=8.14, p=.008$, following the Greenhouse-Geisser correction, Epsilon=.619. The interaction between acceptance of haptic interface and users showed that there was a significant difference, $F(2,10)=6.54, p=.015$, following the GreenhouseGeisser correction Epsilon=.567.

\subsection{Preferred learning style}

A number of elements were used to find the factors for accepting a different type of learning resource. In order to find each individual's preferred learning style, the VARK (visual, aural, reading/writing, and kinaesthetic) learning style questionnaire version 7.2 was used [20, 21]. The analysis used the percentage of $K$ element out of the four different learning styles, since the sample size was relatively small. However, the distribution of different learning styles was similar to the collected data on the VARK site.

Interpretation of the results was based on the four different learning styles and student acceptance of the haptic-anatomy system. Acceptance was calculated based on the responses from these survey items: 1) the system was useful, 2) the system was easy to use, and 3) I would recommend others to use it.

A repeated measure ANOVA showed that there was no significant difference (Fig. 2 ) among the mean of leaning styles, $\mathrm{F}(3,15)=1.01, p=.414$ following the GreenhouseGeisser correction, Epsilon=.169. Bonferroni-adjusted pairwise comparison demonstrated that the mean of acceptance related to the kinaesthetic learning style $(\mathrm{M}=64.44, \mathrm{SD}=6.13)$ was significantly greater than the mean related to the visual learning style $(\mathrm{M}=55.28, \mathrm{SD}=8.83)$. However, this result suggested that readinglearning style was not significantly different from kinaesthetic learning style, $(M=63.61, S D=4.1)$. It also suggested that there was a significant difference between acceptance of students with kinaesthetic learning styles and those with auditory learning styles $(\mathrm{M}=70.83, \mathrm{SD}=3.10)$.

A repeated measure ANOVA revealed that there was a significant difference between the means of acceptance of interface (usefulness, ease, and recommendation), $\mathrm{F}(2,10)=20.88, \quad p<.001$, following the Greenhouse-Geisser correction, Epsilon= .807. Bonferroni-adjusted pairwise comparison demonstrated that the mean of the acceptance usefulness of interface $(\mathrm{M}=75.88, \mathrm{SD}=2.60)$ was significantly greater than the ease of interface $(\mathrm{M}=50, \mathrm{SD}=4.6)$, and recommendation of interface ( $\mathrm{M}=64.80, \mathrm{SD}=2.10)$. 


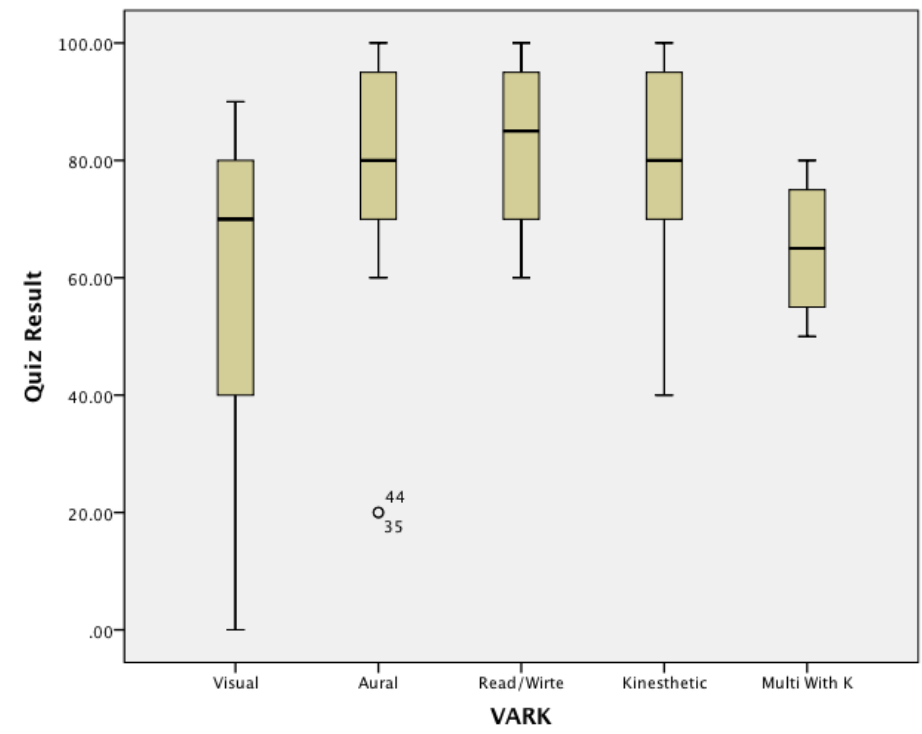

Fig. 2. Comparison of the Quiz results from different groups of learning style

\subsection{Course enrolled and preference of haptics}

As users were enrolled in different courses (see 2.1), a question arose concerning their degrees. For example, Bachelor of Computing (BComp) students used the system more easily than others in different disciplines. User test 1 had $2^{\text {nd }}$ year MBBS and BComp students, user test 2 had MBBS year 1, and user test 3 had MBBS year 1 and other health related courses such as health and physical education, etc. The analysis of variance showed significant main effects and no significant interaction after Greenhouse-Geisser adjustment to the degrees of course enrolled and the acceptance of haptic interface. There is a significant difference of the main effect of the acceptance of the haptic interface, $\mathrm{F}(1,18)=20.49, p<.001$, following the GreenhouseGeisser. A repeated measure ANOVA showed, however, that there was an insignificant difference among the mean of course enrolled, $\mathrm{F}(2,36)=2.78, p=.075$, following the Greenhouse-Geisser. The interaction between current course enrolled and acceptance of haptic interface, showed that there was no significant difference, $\mathrm{F}(2,36)=.792, p=.461$.

The pattern of responses from three different user tests (Fig. 3.) shows that the use of the system may have become harder as the versions advanced, but its usefulness was rated higher than the 'performed well' response. All of the three questions were rated higher by males than females with statistically insignificant differences in acceptance levels for all aspects. 


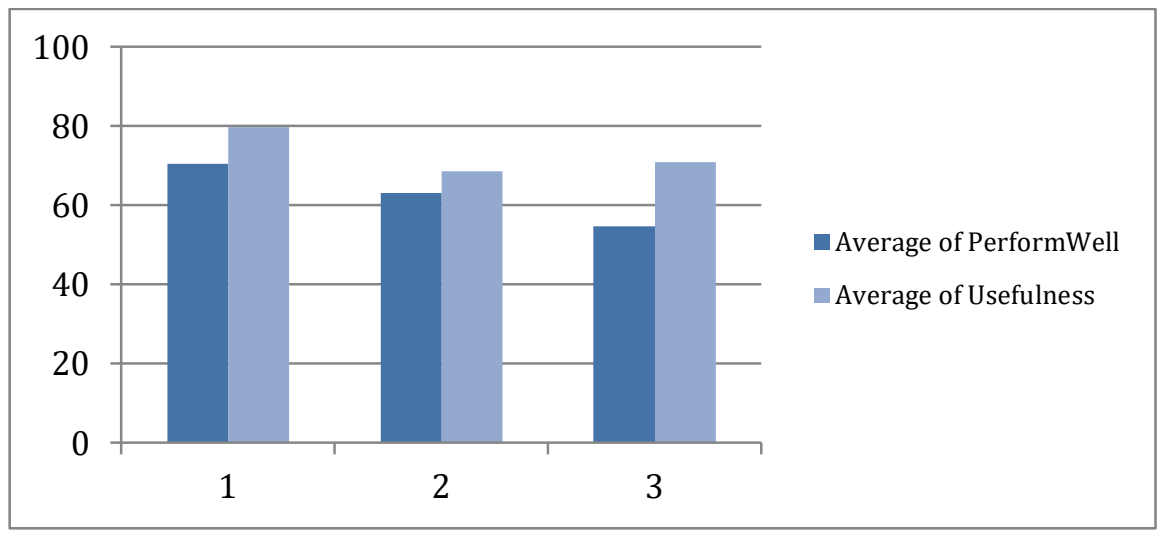

Fig. 5 Three user tests

\subsection{Previous 3D experience}

Quite a number of students identified themselves as having prior experiences with 3D interfaces $(n=63)$ whereas very few users had used haptic interfaces before $(n=15)$. Users with prior experiences with 3D interfaces are more likely to assess the system positively (Fig. 4.). The item, 'would you recommend' was significantly different as $p=0.025$ from t-test between two groups with and without previous 3D interface experience. The post-activity quiz score was $\mathrm{p}=0.050$ with Mann-Whitney $\mathrm{U}$ test, showing another significant difference. Therefore, we could conclude previous experience with a 3D interface made users more likely to accept the haptic learning resource.

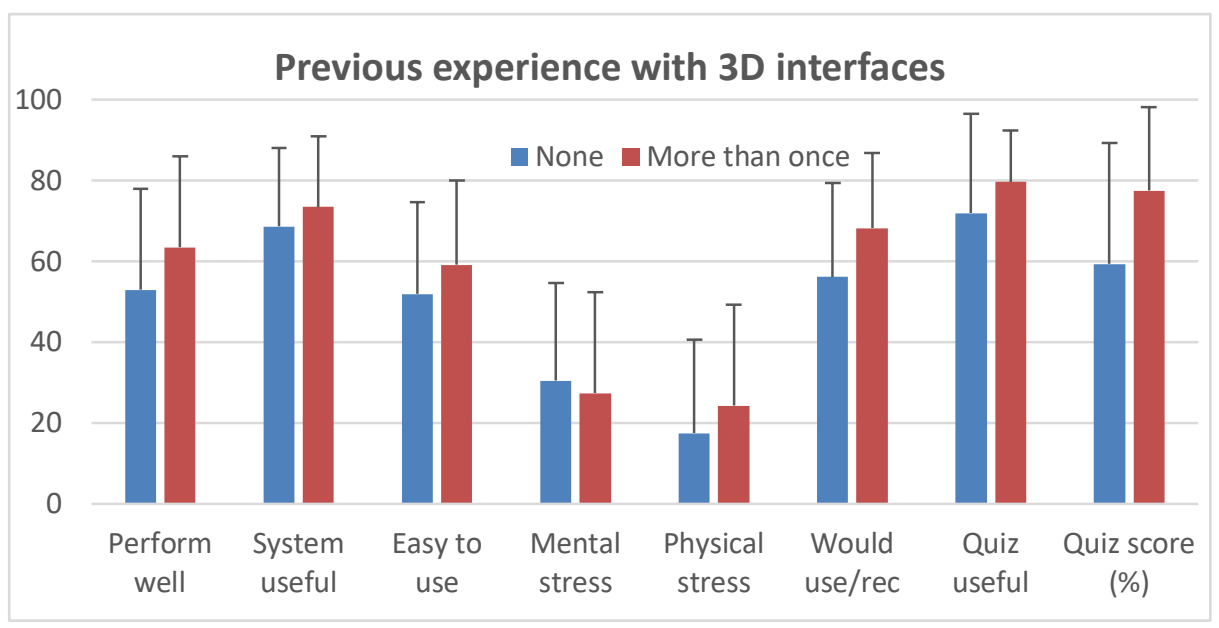

Fig. 6 Responses with/without prior 3D experiences 


\section{Conclusion and Future Direction}

In such an important and difficult subject as anatomy, another type of resource will help students. The availability of different resources, including a haptic system, will assist students who are interested in learning differently.

No significant difference was found in different learning styles. This means, this system works for all different styles of learners, at the same time, it doesn't have any particular benefit to kinaesthetic learners.

However, the significant differences were found in 3D model users. They assessed the system as 'performed well'. Their quiz results were higher than for students without previous 3D experiences. When you have previous experiences with 3D systems, the more positive responses and the higher quiz results were found except the experienced ones found the system was more physically stressful. One thing we need to clarify was if the users were talking about the same level of 3D experiences. Most of them were talking about 3D images of games and other applications, unlike 3D models that can be manipulated as in the system here.

Gender differences were not found in this experiment, unlike most studies in the literature all. This could mean that the haptic system is gender neutral. However, the population for comparison was rather small (under 100 students).

In a future study, we hope to let students explore each anatomical object with their whole hand rather than just a single haptic touch point. This will be more natural for users, and will incorporate tactile (touch sensations) as well as force feedback. As the device develops rapidly, such new devices will add to the kinaesthetic learning experience of the haptic-anatomy system.

Acknowledgments. We thank the University of Tasmania for a Teaching Development Grant which enabled us to explore this new technology in class. Thanks also go to the teaching team and the students involved in the user tests.

\section{References}

1. Yeom S, Choi-Lundberg D, Fluck A, and Sale A.:User Acceptance of a Haptic Interface for Learning Anatomy. International Association for Development of the Information Society International conference on e-Learning (2013).

2. Chuttur M.: Overview of the Technology Acceptance Model: Origins, Developments and Future Directions. Sprouts: Working Papers on Information Systems 9(37)(2009).

3. Craig S, Tait N, Boers D, and McAndrew D.: Review of anatomy education in Australian and New Zealand medical schools. ANZ journal of surgery 80(4):212-216 (2010).

4. Murray N, Qiao Y, Lee B, Muntean G, and Karunakar A.: Age and gender influence on perceived olfactory \& visual media synchronization. In Multimedia and Expo (ICME), 2013 IEEE International Conference on (pp. 1-6). IEEE. (2013).

5. Alipour M, Gorjian B, and Zafari I.: The effects of songs on EFL learners' vocabulary recall and retention: The case of gender. Advances in Digital Multimedia (ADMM). 2012;1(3):140-3 (2012). 
6. Padilla-Meléndez A, Del Aguila-Obra A, and Garrido-Moreno A.: "Perceived playfulness, gender differences and technology acceptance model in a blended learning scenario", Computers \& Education, Vol. No. 63, pp. 306-317 (2013).

7. AlKhasawneh E.: Using VARK to assess changes in learning preferences of nursing students at a public university in Jordan: Implications for teaching. Nurse Education Today. 2013 Dec 31;33(12):1546-9 (2013).

8. Coffield F, Moseley D, Hall E, and Ecclestone K.: Learning styles and pedagogy in post16 learning: A systematic and critical review, London, UK, Learning and Skills Research Centre (2004).

9. Rohrer D, and Pashler H.: "Learning styles: where's the evidence?", Med Educ, Vol. No. 46, pp. 634-5 (2012).

10. Esteban G, Fernández C, Conde MÁ, and García-Peñalvo FJ.: Playing with SHULE: surgical haptic learning environment. Proceedings of the Second International Conference on Technological Ecosystems for Enhancing Multiculturality: ACM. p 247-253 (2014).

11. Ullrich S, and Kuhlen T.: Haptic palpation for medical simulation in virtual environments. Visualization and Computer Graphics, IEEE Transactions on 18(4):617-625 (2012).

12. Tercero CR, Najdovski Z, Ikeda S, Nahavandi S, and Fukuda T.: Haptic feedback in endovascular tele-surgery simulation through vasculature phantom morphology changes. World Haptics Conference (WHC), 2013: IEEE. p 359-364 (2013).

13. Marangunić N. and Granić A.: "Technology acceptance model: a literature review from 1986 to 2013", Universal Access in the Information Society, Vol. No. 14, pp. 81-95 (2015).

14. Zacharis NZ.: Predicting college students' acceptance of podcasting as a learning tool. Interactive Technology and Smart Education 9(3):171-183 (2012).

15. Davis FD, Bagozzi RP, and Warshaw PR.: User acceptance of computer technology: a comparison of two theoretical models. Management Science 35(8):982-1003 (1989).

16. Oh J, and Yoon S-J.: Validation of Haptic Enabling Technology Acceptance Model (HETAM): Integration of IDT and TAM. Telematics and Informatics 4(31):585-596 (2014).

17. Oh E, and Reeves TC.: The implications of the differences between design research and instructional systems design for educational technology researchers and practitioners. Educational Media International 47(4):263-275 (2010).

18. Urval, R. P., Kamath, A., Ullal, S., Shenoy, A. K., Shenoy, N., and Udupa, L. A.: Assessment of learning styles of undergraduate medical students using the VARK questionnaire and the influence of sex and academic performance. Advances in physiology education, 38(3), 216-220 (2014).

19. Mohammadi, S., Mobarhan, M. G., Mohammadi, M., and Ferns, G. A.: Age and Gender as Determinants of Learning Style among Medical Students (2015).

20. Fleming ND.: I'm different; not dumb. Modes of presentation (VARK) in the tertiary classroom. Research and Development in Higher Education, Proceedings of the 1995 Annual Conference of the Higher Education and Research Development Society of Australasia (HERDSA), HERDSA. p 308-313 (1995).

21. VARK Learn Limited. VARK: A guide to learning styles, and research \& statistics (2016). 